\title{
Sentinel node biopsy and radical lymph node dissection for advanced melanoma in the elderly
}

\author{
V Desiato*, S Perrotta, GL Benassai, G Quarto, G Benassai, G Limite \\ From XXIII Annual Meeting of the Italian Society of Geriatric Surgery \\ Lecce, Italy. 2-4 December 2010
}

\section{Background}

The majority of indications for surgery in melanoma are for the treatment of primary tumor and lymph node metastases. During the last decade, the Sentinel Node Biopsy (SNB), from a research procedure, has become standard of care in most institutions. SNB is normally considered for patients with melanoma $>1 \mathrm{~mm}$ and generally about $20 \%$ are positive; however, the risk of a positive SNB in a melanoma $<1 \mathrm{~mm}$ is still $5 \%$. Usually when SNB is positive a complete lymphadenectomy is performed.

\section{Materials and methods}

In the period 2004-2009, 18 elderly patients (median age 68 years) affected by cutaneous melanoma (mean Breslow's thickness $=3.77 \mathrm{~mm}$ ), after SNB histologically confirmed regional lymph node involvement, underwent complete lymph node dissection (CLND). We treated 11 of them with groin dissection, in 3 cases bilateral; 4 patients underwent axillar dissection, in one case bilateral; 2 patients underwent neck dissection and another patient underwent groin-axillar dissection. We treated bilateral groin involvement with laparoscopic access for dissection of lumbar-aortic, iliac and obturator lymph nodes.

\section{Results}

Disagreeing with literature, 12/18 (67\%) of these patients had positive lymph nodes, a high percentage if compared with younger patients' data. Currently the average follow-up is 25 months. In our sample CLND has a crucial prognostic role $(16 \%$ vs $41 \%$ of deceased in CLND - and CLND + patients respectively).

\footnotetext{
* Correspondence: vin_des@hotmail.it

Dipartimento Universitario di Chirurgia Generale, Geriatrica, Oncologica e

Tecnologie Avanzate Facoltà di Medicina e Chirurgia, Università degli Studi di Napoli Federico II, Naples, Italy
}

(c) 2011 Desiato et al; licensee BioMed Central Ltd. This is an open access article distributed under the terms of the Creative Commons Attribution License (http://creativecommons.org/licenses/by/2.0), which permits unrestricted use, distribution, and reproduction in any medium, provided the original work is properly cited.

\section{Conclusions}

Elderly melanoma patients are characterized by a higher tumor stage and, in patients with nodal metastases, the of positive SNB the CLND plays a notable prognostic role and a presumable therapeutic role.

Published: 24 August 2011

\section{References}

1. Marsden JR, Newton-Bishop JA, et al: Revised U.K. guidelines for the management of cutaneous melanoma 2010. Br J Dermatol 2010, 163(2):238-56

2. Testori A, Stanganelli I, et al: Diagnosis of melanoma in the elderly and surgical implications. Surg Oncol 2004, 13(4):211-21.

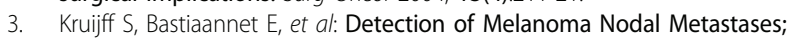
Differences in Detection Between Elderly and Younger Patients Do Not Affect Survival. Ann Surg Oncol 2010, 17:3008-3014.

\section{doi:10.1186/1471-2318-11-S1-A9}

Cite this article as: Desiato et al:: Sentinel node biopsy and radical lymph node dissection for advanced melanoma in the elderly. BMC Geriatrics 2011 11(Suppl 1):A9. prognosis is independently affected by older age. In case and take full advantage of:

- Convenient online submission

- Thorough peer review

- No space constraints or color figure charges

- Immediate publication on acceptance

- Inclusion in PubMed, CAS, Scopus and Google Scholar

- Research which is freely available for redistribution 